\title{
O papel das redes na mobilidade laboral de curta e longa distância: evidências para o Brasil formal
}

\author{
Verônica de Castro Lameira \\ Doutoranda - Universidade Federal de Minas Gerais - CEDEPLAR (UFMG) \\ Endereço: Av. Antônio Carlos, 6627 - Pampulha, Belo Horizonte/MG - Brasil \\ CEP: 31270-901 -E-mail: lameira.veronica@gmail.com
}

\section{Eduardo Gonçalves}

Professor - Departamento de Economia - Universidade Federal de Juiz de Fora (UFJF) Endereço: Campus Universitário - Juiz de Fora - Minas Gerais/MG - Brasil CEP: 36036-330-E-mail: eduardo.goncalves@ufjf.edu.br

\section{Ricardo da Silva Freguglia \\ Professor - Departamento de Economia - Universidade Federal de Juiz de Fora (UFJF) Endereço: Campus Universitário - Juiz de Fora - Minas Gerais/MG - Brasil CEP: 36036-330 - E-mail: ricardo.freguglia@ufjf.edu.br}

Recebido em 08 de julho de 2013. Aceito em 22 de junho de 2014.

\section{Resumo}

Este artigo tem o objetivo de investigar os determinantes da mobilidade de trabalhadores de curta e longa distância entre microrregiões brasileiras no período 2004-2008, com ênfase no papel das redes de mobilidade preestabelecidas. São construídas matrizes de deslocamento por meio da base de dados Rais-Migra, empregando variáveis explicativas na forma de razão destino/origem, e utilizando como arcabouço metodológico os modelos para dados de contagem, a fim de identificar diferenças e similitudes desses fluxos de trabalhadores em relação a diferentes distâncias. Os resultados apresentam evidências consistentes com o histórico de atratividade das regiões para migração, indicando que redes ou conexões prévias facilitam a mobilidade espacial laboral. Além desses resultados, na mobilidade de curta distância o trabalhador se desloca para destinos com maiores densidade e proporção de graduados, além de menores criminalidade, congestionamento e grau de industrialização. Em longas distâncias, os fluxos são orientados para destinos com menores criminalidade, além de maiores saldos entre trabalhadores admitidos e desligados. A distância entre microrregiões sempre figura como fator inibidor da mobilidade, independente dos cortes de distância usados.

\section{Palavras-Chave}

Mobilidade de trabalhadores. Redes de mobilidade. Modelo binomial negativo inflado de zeros.

- Os autores agradecem o apoio financeiro do CNPq e FAPEMIG para realização deste trabalho e o acesso à base de dados RAIS-MIGRA, propiciado pelo Ministério do Trabalho e Emprego (MTE). 


\begin{abstract}
This paper aims to investigate the main determinants of mobility of workers between short and long distance in the Brazilian micro-region from 2004 to 2008, emphasizing the role of established migration networks. Matrices to measure the labor flows are constructed by means of Rais-Migra database as wells as are used explanatory variables as destination/origin ratio. Count data models are used as a methodological framework to identify similarities and differences among the determinants of labor mobility according different distances. The results show evidence in favor of the historical attractiveness of micro-regions for migration, supporting the idea that migration networks or previous personal connections facilitate spatial labor mobility. Beyond these results, for short distance mobility, the workers move to destinations more attractive in relation to dynamic labor markets, higher density of population, higher proportion of more educated workers, lower degree of industrialization and smaller crime rates and vehicles per inhabitants. For long distance mobility, workers are oriented to destinations with lower crime rates and greater attractiveness measured by previous flows. The distance decreases the propensity to migrate for both short and long labor movements as an inhibiting factor for mobility, regardless of the cuts away.
\end{abstract}

\title{
Keywords
}

Mobility of workers, Mobility network, Zero inflated negative binomial model.

\section{JEL Classification}

R23. J61. O15. O18.

\section{Introdução}

Este artigo tem por objetivo investigar os determinantes da mobilidade de trabalhadores de curta e longa distância entre microrregiões brasileiras entre 2004 e 2008, com ênfase no papel das conexões ou redes preestabelecidas. ${ }^{1}$

Os fatores determinantes dos fluxos migratórios inter-regionais são complexos e muito debatidos na literatura. Em geral, argumentos teóricos relacionados a diferenciais de renda e salários, bem como a presença amenidades naturais e urbanas, são apontados como principal causa da migração. A análise dos fluxos migratórios durante

1 O foco deste trabalho é o de analisar a mobilidade laboral. Em razão da base de dados usada Rais-Migra - apenas permitir o acompanhamento longitudinal dos trabalhadores em termos de origem e destino do local de trabalho é importante advertir que no caso de deslocamentos de curta distância, a mudança de local de trabalho pode não representar mudança do local de residência. Por outro lado, para movimentos de longa distância, é provável que a mobilidade do trabalhador coincida com a definição de migração, por envolver, necessariamente, mudança do local de residência. 
muito tempo esteve centrada no desenvolvimento de regiões atrasadas. Sob este prisma, o desafio teórico era elencar variáveis que determinavam a realocação de mão de obra e a orientação desses fluxos, cujas direções originavam-se de regiões atrasadas para regiões com maior desenvolvimento relativo (Ramos e Araújo, 1999).

A importância de se distinguir entre os fluxos migratórios de curta e longa distância é identificada na maioria dos estudos sobre mobilidade. Entretanto, parece evidente a necessidade de maior conhecimento a respeito dos determinantes dos fluxos migratórios de curta e longa distância para o Brasil, tendo em vista que grande parte dos estudos não faz a distinção metodológica desses fluxos, deixando essa discussão no plano teórico. Nesse sentido, pretende-se explorar essa lacuna da literatura empírica de mobilidade com incorporação da distância, até então negligenciada em nível microrregional. Os estudos sobre o tema no Brasil têm se dedicado a explorar os determinantes regionais dos fluxos migratórios, bem como a forma que a distância influencia a decisão de migrar, conforme pode ser constatado em várias contribuições (Sahota, 1968; Golgher et al., 2005; Sabbadini e Azzoni, 2006; Justo e Silveira Neto, 2006; Sachsida et al., 2010).

Os movimentos migratórios no Brasil são relacionados a aspectos históricos da distribuição espacial da população, que ainda possuem influência sobre a migração atualmente. Esses movimentos migratórios podem ser diretamente associados à evolução de características regionais, como as desigualdades regionais na renda per capita e densidade populacional (Golgher et al., 2005).

Nas últimas décadas, destacam-se a complexidade e a diversificação dos deslocamentos populacionais propiciados pelos efeitos advindos do processo de urbanização do país no cenário da mobilidade espacial da população brasileira. Os efeitos desse processo nos movimentos migratórios têm propiciado a expansão dos espaços da migração, com incorporação de novas áreas de absorção populacional. Portanto, para entendimento da migração no Brasil é preciso considerar principalmente as dinâmicas migratórias intrarregionais, pois se podem captar transformações nos fenômenos migratórios desses espaços (Baeninger, 2003). As migrações possuem o poder de construir vínculos duradouros entre pessoas e lugares. Por sua vez, a visão de que as migrações internas dão origem a uma rede de relações entre os lugares, que pode ser investigada na sua estrutura e composição, 
torna-se particularmente útil no estudo dos processos de integração territorial recente no Brasil (Braga e Fazito, 2010).

A integração territorial prévia, caracterizada por uma rede prévia de migrantes, dá origem a posterior fluxo de pessoas, uma vez que facilita a circulação de informações, diminuindo, por sua vez, o risco e a incerteza na decisão migratória. Nesse sentido, percebe-se a importância dos movimentos migratórios na compreensão das formas de conexão territorial. Truzzi (2008), no entanto, discute as dificuldades e as vantagens do conceito de rede em estudos migratórios para explicar tanto as escolhas de destinos quanto a inserção no mercado de trabalho receptor. De acordo com o autor, a noção de redes é crucial a todos os que almejam entender migrações como um processo social, sejam as migrações históricas ou contemporâneas.

Em geral, os estudos que se utilizam da noção de redes sociais não abrangem a discussão empírica, resumindo-se a aspectos qualitativos e teóricos do processo. E quando o fazem, utilizam o arcabouço metodológico de Análise de Redes Sociais (ARS). Dentro dessa perspectiva, o presente trabalho é um esforço empírico pioneiro no que tange à identificação dos fatores que explicam os fluxos de mobilidade laboral entre microrregiões geográficas brasileiras no contexto de redes preestabelecidas por trabalhadores. Ao mesmo tempo, a abordagem adotada permite decompor os fluxos de mobilidade de trabalhadores em curta e longa distância, a fim de modelar os efeitos das redes migratórias, controlando outras variáveis econômicas e amenidades que também podem exercer influência sobre o comportamento da mobilidade laboral.

Os resultados indicam importância do histórico de atratividade das regiões quando são considerados todos os fluxos, inclusive os de longa distância, o que confirma a hipótese de que as redes preestabelecidas facilitam a mobilidade espacial laboral, uma vez que diminuem o grau de incerteza associado ao movimento. Na mobilidade de curta distância, o trabalhador se desloca para destinos com maiores densidade populacional, proporção de trabalhadores graduados e menores graus de industrialização, PIB per capita, taxas de criminalidade e veículos por habitante. Os resultados diferem no modelo de longa distância. O grau de industrialização não apresentou relevância na mobilidade de longa distância, enquanto que, para os movimentos de curta distância, tal variável se mostra negativamente relacionada aos 
fluxos de mobilidade. A distância entre microrregiões de destino e origem figura como fator inibidor para a mobilidade, independente dos cortes de distância usados.

O presente estudo está organizado em cinco seções, além desta introdução. A segunda seção descreve a revisão da literatura internacional e nacional sobre o tema. A metodologia utilizada e a descrição da base de dados são apresentadas na terceira seção, enquanto a quarta descreve os resultados encontrados. Por fim, considerações finais são apresentadas na última seção.

\section{Referencial teórico}

\subsection{Modelos de migração}

O deslocamento da mão de obra tem permeado debates na literatura sobre desenvolvimento econômico e economia do trabalho. Entretanto, os fatores determinantes dos fluxos migratórios inter-regionais, ou da realocação espacial do fator trabalho, são complexos. De um lado, argumentos teóricos atribuem aos fatores de atração nas regiões de destino o motivo para migração, na qual diferenças nas vantagens econômicas, principalmente diferenciais de salário, são a principal causa da migração.

O modelo denominado "desequilíbrio" da migração (Greenwood, 1975; Greenwood e Hunt, 1984) considera a migração inter-regional como fenômeno econômico e subproduto da busca por emprego. Indivíduos reagem ao desequilíbrio inicial em salários e desemprego se movendo para áreas onde o nível de salários é mais elevado e o desemprego é menor, restaurando o equilíbrio no espaço. Sob este prisma, os fluxos migratórios seriam orientados por variáveis econômicas e do mercado de trabalho; regiões com maior renda e menores taxas de desemprego atrairiam migrantes.

A abordagem do "equilíbrio" da migração propôs visão alternativa acerca da migração inter-regional, explicando razões inesperadas entre migração e salário. As diferenças de salário entre as regiões seriam parcialmente compensadas por fatores não econômicos, como clima, temperatura, isto é, amenidades naturais não comercializáveis 
(Graves, 1976, 1980, 1986). A partir da intuição de Graves (1980), outros autores incorporaram outras amenidades, sociais ou culturais, importantes no contexto migratório (Florida, 2002; Shapiro, 2006). De acordo com essa abordagem, os fluxos migratórios seriam dirigidos para regiões menores e com melhor qualidade de vida, sem dominância de variáveis econômicas.

Segundo Jackman e Savouri (1992), a migração regional é estimulada se outras regiões oferecem maior probabilidade de encontrar trabalho do que a região de origem, o que harmoniza diferenças inter-regionais nas taxas de desemprego. Os autores afirmam ainda que a migração é um dos mecanismos capazes de solucionar desequilíbrios no mercado de trabalho. A partir de dados de trabalhadores noruegueses para a década de 1990, Stambol (2003) enfatiza a melhora geral no nível educacional da mão de obra, e aumento da renda dos migrantes laborais frente aos trabalhadores que permanecem no mesmo emprego. O autor conclui que o aumento na renda é ainda maior para os trabalhadores que se movem entre regióes, sendo estes indivíduos mais escolarizados.

Em estudo mais recente sobre a migração laboral nos Estados Unidos, Moretti (2011) observa a concentração de trabalhadores qualificados em cidades com altos custos de vida, e de trabalhadores menos qualificados em cidades com baixos custos de vida, o que pode estar associado à maior presença de amenidades nos destinos de trabalhadores qualificados. Faggian e Royuela (2010) argumentam que ficou claro, ao longo do tempo, que as abordagens do desequilíbrio e equilíbrio para a migração não são irreconciliáveis. $\mathrm{Na}$ migração, indivíduos comparam diferenciais de utilidade em diferentes locais alternativos e estes diferenciais de utilidades são funções tanto de fatores econômicos como de fatores não econômicos, como a qualidade de vida. O ponto principal seria o peso atribuído a cada um desses fatores (Biagi, Faggian e McCann, 2011). De acordo com Lee (1980), os fluxos migratórios estão associados aos pesos atribuídos a fatores nos locais de origem e destino. O saldo desses fatores, que são mediados por obstáculos intervenientes entre a origem e o destino, como a distância envolvida, as barreiras físicas, os custos de transporte e os fatores pessoais, determinam o sentido do fluxo.

Com relação ao papel da distância na migração laboral, Zimmermann (2004) adverte que os riscos e custos de migrar devem aumentar 
com a distância entre origem e destino. Ainda segundo o autor, migrações de longa distância incorrem em maiores custos psicológicos e de obtenção de informação sobre o destino, frente aos movimentos de curta distância. Além disso, a proximidade facilitaria a migração de retorno, em caso de insucesso no primeiro movimento.

A preferência pelas migrações de curta distância é um ponto destacado no estudo de Lucas (2001). Por outro lado, em longas distâncias, uma rede social de migração bem estruturada pode ser determinante para o deslocamento das pessoas (Kanas et al., 2011). Para Guilmoto e Sandron (2001), no ponto em que a decisão de migrar ou não migrar é feita, o desejo chave é minimizar riscos; portanto, tal escolha deve levar em consideração um conjunto de convenções, regras, normas e sistemas de valores que são específicos de cada sociedade e constituem o contexto institucional do processo de migração, o qual permite compreender o estabelecimento de redes e canais dentro do qual a migração individual muitas vezes ocorre.

A literatura sobre migração sugere que há um processo de relativização no conceito de distância, bem como no seu papel sobre os fluxos migratórios nas últimas décadas (Lucas, 2001; Massey et al., 1998; De Haas, 2010; Golgher, 2004). Nesse contexto, estaria ocorrendo uma expansão do papel desempenhado pelas redes sociais na migração, sobretudo, na migração de longa distância, cujos custos são maiores (Kanas et al., 2011; Stark e Jakubek, 2013; Guilmoto e Sandron, 2001).

Conforme Golgher (2004), as diferenças regionais atuam diretamente sobre as razões de permanência ou mudança do local de origem. Baixa qualidade de vida no local de origem e melhor nível de vida no local de destino são fatores determinantes para os fluxos migratórios, respectivamente conhecidos como fatores "push" e "pull". O autor salienta ainda que existem fatores que fazem com que a distância seja apenas um custo aproximado para a migração, haja vista que a existência de uma rede social entre origem e destino pode fazer com que os custos do deslocamento sejam menores e, dependendo da situação, pode-se migrar para uma região distante e, ao mesmo tempo, terem-se custos de migração baixos. 


\subsection{Fluxos migratórios no Brasil}

A migração interna no Brasil é um fenômeno bastante significativo devido à sua magnitude e diversidade econômica e social. Segundo Netto Jr. e Moreira (2003), o processo migratório brasileiro passou a ter expressão a partir da década de 1930, resultado da expansão do setor dinâmico da economia e de fatores climáticos. Entre 19301950, grande parte das migrações internas tinha como destino o estado de São Paulo. A partir da década de 1950, as migrações responderam às consequências da integração entre mercado de trabalho e desenvolvimento industrial.

Sahota (1968) realiza estudo utilizando o Censo de 1950 sobre fluxo migratório entre 19 estados brasileiros, nos quais a distância é uma variável que pode representar mais do que meros custos econômicos. As informações e conhecimentos sobre empregos estão intimamente relacionados com a distância. Diferenças de língua, dialetos, vestuário, alimentação, costumes sociais e culturais são geralmente acentuados pela distância. Incerteza sobre as oportunidades de trabalho podem aumentar com a distância. $\mathrm{Na}$ ausência de uma função de migração completamente especificada, portanto, a distância pode servir como uma variável proxy para os fatores omitidos. Neste estudo, a variável distância é, portanto, utilizada principalmente para os custos econômicos incorridos na viagem, perda de rendimento durante o período de transferência, devendo ser, portanto, negativamente correlacionada com a migração.

De acordo com Jardim (2011), a partir dos anos de 1970, ocorre aprofundamento da internacionalização da economia e sociedades brasileiras. Por conseguinte, para compreender as novas modalidades de migrações internas, cuja dinâmica é típica de sociedades voltadas para o consumo de bens e serviços, passou a existir a necessidade de melhor compreensão dos deslocamentos populacionais interestaduais, inter-regionais, intraestaduais, intermunicipais, intra e intermetropolitanos.

Patarra (2003) salienta que, até a década de 1970, a migração pode ser entendida por um padrão migratório relativamente constante: migrações de longa distância e concentrada nas grandes metrópoles. Segundo a autora, nos anos 80 , ocorrem acentuadas transformações no volume, fluxo e característica dos movimentos migratórios no 
Brasil, sintetizados em menor crescimento das metrópoles, maior predominância das migrações de curta distância e intrarregionais, tendência a crescimento das cidades de médio porte e configuração de periferias em torno de centros urbanos maiores.

A partir da década de 1980, os deslocamentos de população iniciam uma fase de mudança no sentido das correntes principais, de modo que surgem novos eixos de deslocamentos envolvendo expressivos contingentes populacionais onde se destacam: inversão das correntes principais dos estados de Minas Gerais e Rio de Janeiro, redução da atratividade migratória exercida pelo estado de São Paulo, aumento na retenção de população na Região Nordeste, novos eixos de deslocamento populacionais em direção às cidades médias do interior do País (Oliveira, 2011).

De acordo com Ferreira e Matos (2006), houve redinamização do fluxo migratório brasileiro na década de 90 , a partir da reorganização do mercado de trabalho oriunda do ajuste estrutural, mediante abertura ao mercado externo e redução do gasto público. A modernização da economia brasileira permitiu maior possibilidade de mobilidade laboral. Em estudo feito para migração de trabalhadores no mercado formal do Brasil entre 1995 e 2003, os autores investigam em que medida a migração favoreceu o aumento na remuneração recebida pelo trabalhador. Os autores notam que o maior dinamismo do mercado de trabalho fora das grandes aglomerações urbanas tem atraído mão de obra. Ferreira e Matos (2006) observam ainda a concentração de fluxos migratórios no Centro-Sul e atração de mão de obra exercida pela Região Norte a partir da oferta de diferenciais salariais.

Oliveira et al. (2011) observam que os principais movimentos populacionais no Brasil ocorrem dentro das próprias regióes, sugerindo deslocamentos a menores distâncias. Quando se considera distância maior, como na escala inter-regional, nota-se que os fluxos apresentam tendência de redução nos seus volumes.

A partir da investigação das migrações internas do Brasil no decorrer da década de 1990 e início do século XXI, Baeninger (2008) observa novas modalidades de deslocamentos populacionais em esferas locais e regionais, em que os fluxos mais volumosos são compostos de idas -e-vindas, refluxos, reemigração, com um crescente vai-e-vem, com 
o aumento da migração de retorno, o que parece confirmar, segundo a autora, o caráter reversível dos movimentos migratórios internos de longa distância no Brasil.

A despeito das abordagens sobre migração e dos diferentes níveis de análise desses fluxos (regiões, estados, municípios), Ervatti e Oliveira (2011) aludem sobre a preocupação na elaboração de tipologias para as distâncias percorridas pelos migrantes, fundamentada no afastamento entre os centros das cidades de origem e destino, de modo a se obter uma definição mais clara do que seriam movimentos de curta, média e longa distâncias.

Golgher et al. (2005) utilizam modelo gravitacional com objetivo de encontrar variáveis que definam o número de migrantes entre as mesorregiões brasileiras. O autor tem como alicerce teórico o modelo de capital humano, o qual pressupõe que a migração é causada pela heterogeneidade espacial entre oferta e demanda por trabalho. Os autores notam que o tamanho da população, tanto na região de origem quanto na região de destino, e a distância entre as regiões, são decisivos na migração.

Os custos inerentes ao deslocamento são também decisivos na análise da ocorrência ou não da migração. Se os custos são baixos, qualquer pequena diferença positiva nos benefícios esperados entre o destino e a origem pode promover a migração da pessoa. Pelo contrário, se os custos são muito elevados, a probabilidade de mudança é muito menor. Os custos de migração podem ser relacionados a aspectos diferentes, como: materiais, busca de informação, psíquicos, oportunidade, processo de adaptação etc. Acredita-se que a distância é bem correlacionada com os custos, sendo aquela uma boa proxy destes (Golgher, 2005).

Sabbadini e Azzoni (2006) realizam estudo empírico a partir de matrizes de origem e destino, construídas a partir dos microdados dos censos demográficos de 1991 e 2000 com objetivo de observar a magnitude da migração interestadual de pessoal altamente qualificado (mestres e doutores) e sua relação com a heterogeneidade da economia brasileira. Os autores analisam a localização desses indivíduos, os principais fluxos no país e a taxa líquida de migração de cada estado, bem como seus padrões espaciais. Posteriormente, é estimado um modelo gravitacional a fim de explicar o fenômeno mi- 
gratório. Os resultados revelam bom ajuste do modelo gravitacional para explicar os determinantes do fenômeno migratório. Ademais, as variáveis renda e qualidade de vida, medida pelo IDH, foram importantes no destino e afetaram positivamente a migração. Verificou-se que estados com menos programas de pós-graduação, controlados outros determinantes, receberam mais migrantes altamente qualificados, sendo, portanto, beneficiados da fuga de cérebros.

Efeitos dos determinantes locais da migração interestadual no Brasil são investigados por Justo e Silveira Neto (2006), verificando que a migração entre duas regiões é afetada pelas condições locais ponderadas pela distância e população. Os autores concluem que se o estado é mais distante ou se é menos populoso, menor é a taxa líquida migratória, o que significa que a capacidade de atração de um estado depende de onde ele está situado em termos de vizinhança. Notam ainda que, quando são utilizadas as oportunidades de cada estado específico, isto é, a atratividade relacionada a fatores sociais e naturais, usando distância e população, é possível obter maior precisão na captura dos efeitos das variáveis explicativas, encontrando ainda uma relação negativa entre criminalidade e taxa líquida de migração.

Mata et al. (2007) buscam compreender quais fatores são relevantes para atrair mão de obra qualificada em municípios do Brasil. Os autores destacam a preferência dos migrantes qualificados por regiões com maiores amenidades sociais e climáticas, isto é, menor desigualdade social, invernos e verões menos rigorosos, menores taxas de homicídios, e ainda, que maior migração de mão de obra qualificada líquida de municípios vizinhos acarreta menor absorção de migrantes qualificados da cidade em questão.

Sachsida et al. (2010) verificam a influência da distribuição de renda e das transferências governamentais no fluxo de imigrantes entre os estados brasileiros. Os resultados econométricos encontrados pelos autores apontam que transferências federais estimulam o fluxo imigratório, enquanto alta concentração de renda possui resultado inverso, prevalecendo o deslocamento para estados com rendas mais altas, mais privilegiados pelas transferências governamentais e mais populosos. Salientam ainda que a distância é a variável em nível individual com maior poder explicativo para esses fluxos, o que aponta para a grande relevância dos custos de transporte sobre fluxos migratórios. 
A literatura sobre migração no Brasil sugere maior importância dos fatores regionais na determinação dos fluxos migratórios. Destaca o efeito negativo da distância sobre a migração (Sahota, 1968; Golgher et al., 2005; Sabbadini e Azzoni, 2006; Sachsida et al., 2010). Além disso, realça o efeito positivo da renda per capita, densidade populacional e salário médio no destino (Sahota, 1968; Golgher et al., 2005, Sabbadini e Azzoni, 2006). As variáveis índice de Gini no destino, custo de transporte até a capital mais próxima e homicídios de jovens exercem efeitos negativos sobre os migrantes (Justo e Silveira Neto, 2006; Sabbadini e Azzoni, 2006; Mata et al., 2007).

\subsection{Redes sociais e migração interna no Brasil}

Muitas questões essenciais ficam sem resposta no conjunto das teorias migratórias que atribuem o movimento migratório ora a uma decisão pessoal, ora a um reflexo das determinações do sistema econômico (Matos e Braga, 2004). Por conseguinte, muitos estudos têm se debruçado sobre a relação entre redes sociais e migração (Soares, 2002; Matos e Braga, 2004; Braga e Fazito, 2010; Lima e Braga, 2010; Cunha et al., 2013).

De acordo com Soares (2002), as redes sociais desempenham papel crucial no processo migratório. Dessa forma, estudos sobre migração devem considerar o migrante não apenas em função de atributos pessoais, mas sim como uma entidade que possui relações atreladas a outros conjuntos, tais como, laços de parentesco, amizade, conhecimento e trabalho, considerando, sobretudo, as possibilidades criadas pelo conjunto de relações nas quais o indivíduo se insere.

Os fluxos migratórios sintetizam parte significativa das conexões estabelecidas entre os lugares, já que, geralmente, a decisão de para onde migrar apoia-se na preexistência de laços econômicos, culturais, afetivos, solidários, entre outros, entre os lugares. Neste sentido, o reconhecimento dos novos padrões migratórios sob a ótica da participação dos lugares pode revelar aspectos mais amplos do que aqueles relacionados à temática da migração interna (Lima e Braga, 2010).

Fazito (2002) adverte que é preciso diferenciar a "rede social na migração" da "rede migratória" propriamente dita. Quando se fala de "rede migratória", na perspectiva da Análise de Redes Sociais (ARS), 
especifica-se um tipo de rede social que tem como elementos fundamentais os fluxos populacionais trocados por regióes ou territórios que compõem um sistema social. No caso das redes sociais na migração, salienta-se o conteúdo e diversas dimensões das relações sociais que participam no processo social da migração.

Braga e Fazito (2010) analisam o papel das redes sociais na migração a partir de matrizes de trocas migratórias entre microrregiões brasileiras construídas com microdados dos Censos Demográficos de 1980, 1991 e 2000. Os autores consideraram os fluxos migratórios entre microrregiões como um indicador das relações sociais, observando a integração do território em função da evolução da rede migratória interna, concluindo que a rede migratória vem aumentando a quantidade de ligações entre os lugares, reduzindo as barreiras e as distâncias para integração do território nacional.

O método oriundo da ARS é utilizado por Cunha et al. (2013) com objetivo de compreender a migração intrametropolitana da Região Metropolitana de Campinas (RMC) entre 1991 e 2000 a partir dos Censos Demográficos. Os autores, contudo, não se atêm às relações e interações sociais estabelecidas entre indivíduos, que seria o sentido mais estrito da ARS. À semelhança dos trabalhos que buscam explicar a relação entre migração e redes sociais (ainda que em sentido mais amplo), esse artigo, embora não utilize o mesmo arcabouço metodológico (o de ARS), parte do pressuposto que a conexão estabelecida reflete um tipo de interação. Nesse sentido, quanto maior o número de interações, possivelmente, maior será o número de recursos, informações e, principalmente, oportunidades, sejam elas de moradia ou emprego, que ocorrem no interior da rede migratória (Cunha et al., 2013). Vale ressaltar que, no que compete aos trabalhos realizados em âmbito nacional, até onde é de conhecimento dos autores, não existe na literatura sobre fluxos migratórios de trabalhadores a separação desses fluxos para diferentes distâncias, tampouco considerando o papel das redes, sendo este estudo pioneiro nesse aspecto. 


\section{Estratégia empírica}

O número de trabalhadores migrantes recebidos pelas microrregiões de destino constitui-se dados de contagem. Tendo em vista que a variável dependente é representada por números inteiros e não negativos, requer-se o uso de modelos de dados de contagem (Cameron e Trivedi, 1998). O modelo de Poisson representa uma alternativa para o tratamento desses dados de contagem, entretanto, este possui suposições restritivas quanto à dispersão dos dados, isto é, que a média condicional é igual à variância condicional. Esse modelo possui especificação de acordo com a Equação l:

$$
\mathrm{f}_{\mathrm{y}}(\mathrm{y}, \mu)=\mathrm{e}^{-\mu} * \frac{\mu}{\mathrm{y} !}, \mathrm{y}=0,1,2, \ldots
$$

Em que y é um número estritamente não negativo, representando o número de ocorrências da variável dependente, e $\mu$ o número esperado de ocorrências, denominado também de parâmetro intensidade ou taxa. Como há apenas um parâmetro na distribuição de Poisson, a igualdade entre média e variância é assumida (equidispersão de dados), que pode ser representado da seguinte forma:

$$
\mu_{i}=\exp \left(x_{i} \beta\right)=E\left[y_{i} \mid x_{i}\right]=\operatorname{Var}\left[y_{i} \mid x_{i}\right]
$$

Em que x corresponde ao vetor de variáveis independentes.

A suposição de equidispersão é uma restrição da distribuição de Poisson, que, em muitos casos, não encontra respaldo nos dados. Quando isso acontece, o modelo de Poisson convencional produz graves distorções nas estimativas dos parâmetros (Cameron e Trivedi, 2005). O modelo de Poisson supõe que o parâmetro de intensidade $\mu$ é determinístico. Em geral, essa suposição não é válida. Este parâmetro é uma função de características observáveis, entretanto, algumas características relevantes não podem ser observadas e, portanto, são negligenciadas no vetor de covariadas. Uma vez que não é possível modelar tais características, faz-se necessário incluir um termo randômico a fim de controlar a heterogeneidade não observada. Negligenciar essa particularidade pode causar sobredispersão dos dados, implicando variância maior do que a suposta pelo modelo. 
Por meio de uma análise da variável dependente, é possível descobrir se os dados são sobredispersos. Nesse estudo, a distribuição não atende à hipótese básica de equidispersão de dados, observada a partir da análise descritiva, que revela ser a média menor do que a variância. Isso foi confirmado também, com base no valor do parâmetro de dispersão $(\alpha)$ estimado nos modelos. Verifica-se ainda que há excesso de zeros na variável dependente, indicando necessidade da estimação do modelo binomial negativo inflado de zeros. ${ }^{2}$

$\mathrm{Na}$ literatura existem duas possibilidades de solucionar o problema de sobredispersão e excesso de zeros, a saber: o modelo Binomial Negativo e Modelo Binomial Negativo Inflado de Zeros. O primeiro trata a sobredispersão como resultado de heterogeneidade não observada, incorporando ao modelo de Poisson um componente aleatório com distribuição Gama. O segundo atribui ponderação diferenciada para valores nulos (Wooldridge, 2002).

O fenômeno de sobredispersão pode ocorrer com dados de contagem quando a variância da variável resposta é maior do que a média. Nesses casos, a suposição de distribuição de Poisson para a resposta é inadequada, uma vez que esse modelo subestima a quantidade de dispersão da variável dependente. Uma causa provável desse fenômeno é a heterogeneidade das unidades amostrais que pode ser devido à variabilidade entre unidades experimentais. Uma investigação simples da variável dependente permite verificar sobredispersão dos dados.

A maneira tradicional de tratar a sobredispersão dos dados é a utilização de modelos de mistura. Esses modelos explicitam a heterogeneidade entre as observações do modelo, adicionando um parâmetro extra, que é função da heterogeneidade não observada. A média representada na Equação 2 é substituída pela expressão da Equação 3:

$$
\mu_{i}^{*}=\exp \left(x_{i} \beta\right) \exp \left(\varepsilon_{i}\right)
$$

E cuja densidade de probabilidade possui a seguinte forma:

$$
\operatorname{Pr}(Y=y \mid \mu, \alpha)=\frac{\Gamma\left(\alpha^{-1}+y\right)}{\Gamma\left(\alpha^{-1}\right) \Gamma(y+1)}\left(\frac{\alpha^{-1}}{\alpha^{-1}+\mu}\right)^{\alpha^{-1}}\left(\frac{\mu}{\mu+\alpha^{-1}}\right)^{y}
$$

2 Cabe ressaltar que a inflação de zeros é em parte devido à base de dados utilizada que contém poucas observações para migrantes. Agradecemos esse ponto ao parecerista anônimo. 
Em que o $\Gamma$ indica a função Gama padrão, e $\alpha$ representa o grau de dispersão dos dados. Quanto maior $\alpha$, mais dispersos são os dados. Quando $\alpha=0$, o modelo binomial negativo se reduz ao modelo de regressão de Poisson. O modelo binomial negativo é não linear e é usualmente estimado pelo método da Máxima Verossimilhança.

Apesar de tratar o problema da superdispersão dos dados, o modelo binomial negativo não lida com a presença de excesso de zeros. Para lidar com essa limitação, os modelos inflados de zero foram desenvolvidos. Os modelos inflados de zero dividem a amostra em dois grupos, realizando as estimações para um grupo que possui apenas zeros na variável dependente (zero estrutural), e outro grupo que pode assumir valor igual ou maior que zero na variável dependente (zero suscetível), o que representa a amostra completa. A partir dessa divisão é gerado um componente logístico que compara a probabilidade da observação fazer parte de um dos grupos.

Os coeficientes estimados pelos modelos Binomial Negativo e Binomial Negativo Inflado de Zeros não são diretamente comparáveis, uma vez que possuem média condicional diferentes. Segundo Cameron e Trivedi (2005), o teste LR de Vuong é utilizado a fim de descriminar entre os dois modelos. Esse teste não possui hipótese nula a priori, com grandes valores positivos favorecendo o modelo inflado de zeros, e valores muito negativos favorecendo o modelo Binomial Negativo. Em primeiro lugar, estimam-se os modelos de Poisson e binomial negativo a fim de testar a especificação do modelo binomial negativo. Efetua-se o teste da razão de verossimilhança para verificar se os dados são sobredispersos, testando as seguintes hipóteses:

$$
\begin{aligned}
& \mathrm{H}_{0}: \alpha=0 \\
& \mathrm{H}_{1}: \alpha>0
\end{aligned}
$$

O teste da Razão de Verossimilhança (LR) é obtido através da diferença entre o logaritmo da verossimilhança do modelo de Poisson e do binomial negativo:

$$
L R=-2\left(L N_{\text {Poisson }}-L N_{\text {Binneg }}\right)
$$


Em que:

$L N_{\text {Poisson }}=$ logaritmo da verossimilhança do modelo de poisson.

$L N_{\text {Binneg }}=$ logaritmo da verossimilhança do modelo binomial negativo .

Quando a hipótese $\mathrm{H}_{0}$ é aceita, o modelo binomial negativo se reduz ao modelo de Poisson, e a estatística LR $=0$.

Posteriormente, testa-se o modelo binomial negativo inflado de zeros frente ao binomial negativo. Para tanto, estimou-se o modelo binomial negativo e, em seguida, sua versão inflada de zeros. A etapa seguinte consistiu na realização do teste de Vuong, apresentado junto à tabela de resultados.

A Tabela A2 do apêndice apresenta os resultados dos testes da razão de verossimilhança do modelo de Poisson contra o modelo binomial negativo para a amostra total (sem recortes de distância), curta e longa distâncias. Em todas as comparações, o uso do modelo de Poisson se revelou inapropriado frente ao modelo binomial negativo. O modelo Poisson inflado de zeros (ZIP) também foi testado frente ao modelo binomial negativo inflado de zeros (ZINB); no entanto, o teste de razão de verossimilhança confirmou melhor ajuste do modelo binomial negativo inflado de zeros.

\subsection{Descrição dos dados e variáveis}

A fim de analisar a mobilidade de trabalhadores com vínculo empregatício formal entre as microrregiões do Brasil a diferentes distâncias são construídas matrizes de origem-destino a partir de uma amostra aleatória da base de dados Rais-Migra para o período 2003-2008, sendo construído um total de cinco matrizes, a saber: 2004, 2005, 2006, 2007 e 2008.

As microrregiões são constituídas pela produção propriamente dita, distribuição, troca e consumo, incluindo atividades urbanas e rurais. Dessa forma, ela expressa a organização do espaço a nível micro ou local. (IBGE, 1990). Soma-se a isso, a escolha de microrregiões 
como unidade espacial de análise se deveu, principalmente, a não subestimação dos fluxos de mobilidade ao se considerar Unidades da Federação; à minimização do efeito da pendularidade, em relação à escolha de municípios, e ainda, em virtude da construção das matrizes de transição e de distância que, no caso das microrregiões, é da ordem de 558 x 558.

Compete salientar que a variável dependente dos modelos, obtida pelas matrizes, corresponde ao estoque de trabalhadores migrantes da microrregião de origem i para a microrregião de destino $\mathrm{j}$, constituindo uma matriz de dimensão 558 x 558. Excluindo-se a diagonal principal $(i=j)$, tem-se um total de 310.806 observações em cada ano (combinações de origem-destino), o que corresponde a um painel de 1.554 .030 observações. Tendo em vista a proposta investigativa do presente estudo, o banco com 1.554.030 observações foi subdividido a partir de diferentes distâncias a fim de captar as diferenças e similitudes para a mobilidade de curta e longa distância entre as microrregiões brasileiras. Foi definido como curta distância o deslocamento do trabalhador entre microrregiões a uma distância igual ou menor a 150 quilômetros, ${ }^{3}$ e longa distância caso contrário. Quanto às variáveis explicativas, essas foram construídas pela proporção destino/origem a fim de considerar tanto os fatores de atração quanto de expulsão, essas são medidas no ano anterior à mobilidade. O Quadro 1 apresenta a descrição das variáveis utilizadas na análise empírica.

A dimensão do mercado de trabalho no destino em relação à origem é capturada pela variável admissões líquidas. O sinal positivo do coeficiente desta variável sugere que, quanto maior a proporção entre admitidos menos desligados do destino em relação à origem, isto é, quanto maior for a criação líquida de emprego na microrregião de destino frente às oportunidades líquidas na origem, maior será a quantidade de migrantes recebida pela microrregião de destino.

Com objetivo de capturar a conexão preestabelecida pelo histórico de mobilidade laboral, indicativa do grau de atração ou expulsão do destino em relação à origem, construiu-se a variável Índice de

3 Foram realizadas regressões com critérios de distâncias diferentes, a saber: curta distância $\leq$ 100 km, e longa distância $>100 \mathrm{~km}$; curta distância $\leq 200 \mathrm{~km}$ e longa distância $>200 \mathrm{~km}$; curta distância $\leq 250 \mathrm{~km}$ e longa distância $>250 \mathrm{~km}$; curta distância $\leq 300 \mathrm{~km}$ e longa distância $>$ 300 ; curta distância $\leq 350 \mathrm{~km}$, e longa distância $>350 \mathrm{~km}$; curta distância $\leq 400 \mathrm{~km}$, e longa distância $>400 \mathrm{~km}$. Os resultados, em geral, são os mesmos, indicando robustez da especificação do modelo a diferentes cortes de distância. 
Eficácia Migratória do destino j em relação à origem i, representada pela razão da diferença entre entradas e saídas sobre a soma desses fluxos de trabalhadores entre microrregião de destino e origem nos três últimos anos anteriores à mobilidade. Esse índice é adaptado de Oliveira et al. (2011), em que foi usado para analisar o fenômeno migratório em termos relativos no Brasil. Segundo os autores, o índice relaciona a imigração líquida observada em determinada microrregião com o fluxo total de migrantes. Assim, seja $I_{i}$ o volume total de imigração observado na microrregião $i$ e $E_{i}$ o volume de emigração, então a estatística IEM será dada por: $I E M_{i}=\frac{I_{i}-E_{i}}{I_{i}+E_{i}}$. No caso deste trabalho, seu uso se justifica porque parte da literatura sinaliza que a migração pode ter uma inércia proveniente das redes formadas entre migrantes anteriores e trabalhadores predispostos a saírem do seu local de origem (Golgher, 2004). Com o Índice de Eficácia Migratória pretende-se captar a mesma influência no caso da mobilidade de trabalhadores, à medida que destinações com saldo positivo no passado podem sinalizar boas oportunidades para trabalhadores que se movem no presente. Como se considera uma defasagem temporal dessa variável em relação ao estoque de trabalhadores que moveram no período analisado, o efeito de uma possível endogeneidade estaria sendo amenizado.

A fim de captar a provável maior mobilidade em baixíssimas distâncias entre microrregiões contíguas, foi criada uma dummy de contiguidade segundo a matriz de contiguidade Queen. Vale lembrar que esse fenômeno deve ocorrer para regiões metropolitanas que se localizam em mais de uma microrregião. Optou-se por criar uma variável a fim de refletir o grau de competitividade do mercado de trabalho com a qual o indivíduo se depara ao mover-se entre microrregiões.

A variável proporção de trabalhadores com ensino superior completo representa a relação entre o estoque de trabalhadores com ensino superior e o estoque total de trabalhadores da microrregião. O sinal negativo do coeficiente dessa variável indica que quanto maior a quantidade de profissionais com nível superior completo no destino, em relação à origem, menor a mobilidade para este destino, uma vez que a concorrência por postos de trabalho tende a ser maior no destino (Beals et al., 1967). Por outro lado, o sinal positivo para essa variável pode revelar ganhos relacionados ao transbordamento de conhecimento (Moretti, 2011), uma vez que trabalhadores procurariam 
localidades com elevado percentual de profissionais com maior grau de escolaridade a fim de interagir e extrair benefícios dessa interação, elevando o nível de capital humano dos trabalhadores migrantes. Argumento similar é exposto também em Glaeser (1999), quando explica que trabalhadores jovens mudam-se para grandes cidades em busca de interações vantajosas com trabalhadores experientes.

O PIB per capita compreende a prosperidade econômica da microrregião de destino frente à origem. Quanto maior o nível de renda da região em relação à origem, maior a atração exercida por esta região (Sahota, 1968; Justo e Silveira Neto, 2006; Biagi et al., 2010; Aldashev e Dietz, 2012).

\begin{tabular}{|c|c|c|c|}
\hline Variáveis & Descrição & Média & Desvio-padrão \\
\hline Variável dependente & $\begin{array}{l}\text { Estoque de trabalhadores recebidos pela microrregião j } \\
\text { procedentes da microrregião i. (Rais-Migra). }\end{array}$ & 0,126 & 8,801 \\
\hline Contiguidade & $\begin{array}{l}\text { Variável dummy que assume valor } 1 \text { se as microrregiões } \\
\text { de origem e destino forem vizinhas, e zero caso contrário. }\end{array}$ & 0,009 & 0,009 \\
\hline Admissões líquidas & Admitidos menos desligados (CAGED/MTE). & 11,739 & 606,267 \\
\hline IEMij & $\begin{array}{l}\text { Relação entre o saldo de mobilidade e o volume total de } \\
\text { mobilidade - nos três últimos anos anteriores à decisão de } \\
\text { mobilidade (Rais-Migra). }\end{array}$ & 0 & 0,234 \\
\hline Densidade populacional & Número de habitantes por quilômetro quadrado (IPEADATA). & 12,697 & 130,046 \\
\hline Veículos/habitantes & $\begin{array}{l}\text { Número total de veículos automotores dividido pela popula- } \\
\text { ção (Sistema de Registro Nacional de Veículos Automotores } \\
\text { - RENAVAN / DENATRAN). }\end{array}$ & 20,048 & 468,542 \\
\hline PIB per capita & $\begin{array}{l}\text { PIB da microrregião dividido pela população residente } \\
\text { (IPEADATA). }\end{array}$ & 1,587 & 1,846 \\
\hline Ensino superior & $\begin{array}{l}\text { Estoque de trabalhadores com ensino superior completo } \\
\text { da microrregião dividido pelo estoque de trabalhadores da } \\
\text { microrregião (RAIS/MTE). }\end{array}$ & 26,299 & 647,376 \\
\hline Distância & $\begin{array}{l}\text { Distância entre as microrregiões de origem e destino, em } \\
\text { quilômetros (GOOGLE MAPS). }\end{array}$ & 2006,331 & 1181,492 \\
\hline Grau de Industrialização & $\begin{array}{l}\text { Proporção de trabalhadores nas indústrias extrativas e de } \\
\text { transformação dividido pelo total de trabalhadores da eco- } \\
\text { nomia (RAIS/MTE). }\end{array}$ & 5,429 & 77,662 \\
\hline Taxa de Homicídio & $\begin{array}{l}\text { Total de ocorrências de homicídio por } 100.000 \text { habitantes } \\
\text { (IPEADATA). }\end{array}$ & 1,977 & 3,593 \\
\hline
\end{tabular}

Quadro 1: Descrição das variáveis.

Nota: todas as variáveis representam a proporção destino/origem.

Fonte: Elaboração própria. 
A variável densidade populacional está relacionada ao porte da cidade e à disponibilidade de serviços e emprego, e ainda a externalidades negativas. Um maior número de pessoas na região de destino pode refletir ainda superlotação, propensão ao surgimento de criminalidade, favelas, poluição, o que desestimularia a mobilidade. O sinal negativo do coeficiente dessa variável indica que as pessoas são menos propensas a se mover para regiões mais urbanizadas, com maior densidade populacional (Hazans, 2003). Por outro lado, um sinal positivo do coeficiente indicaria maiores oportunidades em regiões densamente povoadas (Sahota, 1968; Levy e Wadycki, 1974; Golgher et al., 2005; Sachsida et al., 2010; Aldashev e Dietz, 2012). Por essas razões, não se pode prever, a priori, seu efeito sobre a variável dependente (Sahota, 1968).

Construiu-se, a partir dos dados da Rais, a variável grau de industrialização, sendo esta a razão entre o total de trabalhadores das indústrias de transformação e extrativa, e o total de trabalhadores na economia. Se o sinal for positivo, isso significa que microrregiões com alto grau de industrialização no destino, em relação à origem, atraem trabalhadores. Por outro lado, um sinal negativo para essa variável é condizente com a criação de novas oportunidades em locais menos industrializados.

A distância é medida em quilômetros lineares entre as microrregiões de origem e destino. Quanto maior a distância, menor será o fluxo de trabalhadores entre as microrregiões, ou seja, espera-se um impacto negativo da distância sobre fluxos migratórios (Schwartz, 1973). Essa variável foi construída com base em uma matriz de distâncias, que foram obtidas na plataforma on-line do sítio Google Maps, que é o serviço especializado da empresa Google em distâncias rodoviárias (em $\mathrm{Km})$.

A variável veículos/habitantes funciona como proxy para congestionamento do trânsito e emissão de $\mathrm{CO} 2$ que reflete o nível de poluição da microrregião. Quanto maior for essa proporção, menor poderia ser a probabilidade de a microrregião receber trabalhadores, ou seja, espera-se que o coeficiente dessa variável tenha sinal negativo.

A variável taxa de homicídio é um indicador da qualidade de vida. Alta criminalidade é entendida como expectativa de vida relativamente curta. Se uma região possui baixa criminalidade será prefe- 
rida como destino. Logo, espera-se sinal negativo para o coeficiente dessa variável.

Vale lembrar que a Rais oferece vantagens no estudo da migração interna que justificam sua utilização em estudos sobre o papel das redes na conexão territorial brasileira. A base de dados Rais-Migra permite investigar as migrações controlando a origem e o destino dos migrantes anualmente. O uso destas variáveis permite a construção de matrizes de origem/destino para todas as subdivisões territoriais, com abrangência amostral para todo o país, permitindo captar: a dinâmica do mercado de trabalho, verificar a atração de mão de obra, mensurar volumes de trabalhadores atraídos por cada lugar e quantidade de conexões; verificar como as redes estabelecidas entre regiões são sintetizadas pela migração, e ainda como se expressam na escolha de determinados destinos ilustrados pela composição dos fluxos.

Frente aos Censos Demográficos, que possuem periodicidade decenal, a base de dados utilizada nesse estudo permite o acompanhamento anual dos fluxos de mobilidade laboral. Entretanto, a RaisMigra, possui desvantagens para o estudo da migração, quais sejam: não há informação sobre o domicílio do indivíduo, características familiares e informação sobre o mercado de trabalho informal. Sobre esse último ponto, vale ressaltar que os resultados do Censo de 2010 mostraram um percentual de pessoas (de 10 ou mais anos de idade) sem carteira de trabalho assinada de $28,5 \%$ do total de empregados no Brasil (IBGE, 2012).

\section{Resultados}

\subsection{Análise descritiva: as redes de mobilidade dos trabalhadores bra- sileiros formais}

Os fluxos de mobilidade dos trabalhadores com vínculo empregatício formal de 2004 a 2008 podem ser observados na Figura 1. Em sua maioria, os fluxos são dirigidos às áreas mais próximas. Nota-se intensa conexão entre as microrregiões dos estados Rio de Janeiro e São Paulo, especialmente entre as microrregiões que contém as capitais paulista e carioca. 
Embora Brasília, São Paulo, Minas Gerais e Rio de Janeiro estabeleçam conexões majoritariamente a curtas distâncias, suas interações alcançam microrregiões relativamente distantes nas Regiões Norte, Nordeste e Sul do País. As microrregiões que contém as Regiões Metropolitanas de São Paulo e Rio de Janeiro distribuem pessoas às áreas distantes no Nordeste e Norte. Este ponto se faz importante uma vez que estes movimentos podem estar traduzindo migração de retorno para o Nordeste e Norte. Enquanto as mobilidades verificadas entre microrregiões mais próximas podem estar associadas à mobilidade pendular, que não é objeto de pesquisa deste artigo. Esta falta de sensibilidade da mobilidade em relação à distância pode de fato estar se traduzindo em algum dos tipos de migração.

No Norte do Brasil, as microrregiões Manaus e Belém atraem pessoas de longas distâncias. Esse fato é coerente, devido à grande dispersão das localidades nessa enorme área. Manaus mantém forte conexão com São Paulo, Rio de Janeiro e Brasília em todos os anos observados, provavelmente por causa da Zona Franca, que cria oportunidades para trabalhadores dos centros mais desenvolvidos. Assim, foi possível verificar a manutenção dos laços entre o Norte e o CentroOeste; muitos trabalhadores transitam entre a Região Norte e o Rio de Janeiro, a microrregião do Sudeste, que estabelece uma rede de mobilidade expressiva com o Norte. Além disso, o Rio de Janeiro também mantém conexão direta com Brasília.

Outro ponto importante a ser destacado é a forte interação entre as capitais nordestinas em seus respectivos estados. Aliás, esse também é o padrão espacial de muitas outras microrregiões importantes do País, tais como aquelas onde se localizam as áreas metropolitanas de Goiânia, Belo Horizonte e Porte Alegre, Santa Catarina, que exercem a função de redistribuir ou movimentar trabalhadores para os seus entornos, um papel característico, portanto, de polos importantes em seus respectivos estados, também verificado para as maiores metrópoles nacionais, São Paulo e Rio de Janeiro. Outro aspecto a ser salientado é a alta densidade da mobilidade laboral formal sobre o território nacional, isto é, praticamente todo o País participa desse fluxo de trabalhadores, formando um complexo emaranhado de fluxos laborais ou redes de mobilidade. 
Entre os anos analisados, as redes de mobilidade não sofreram grandes mudanças no que se refere ao padrão dos locais de origem e destino destes fluxos no País. De fato, a Microrregião de São Paulo continua sendo a principal centralidade dessa rede, mantendo forte interação com seu entorno, especialmente com a Microrregião de Campinas que, por sua vez, interage com o interior do próprio estado.

Neste período, a quase totalidade das principais origens e destinos dos trabalhadores continha uma região metropolitana ou uma capital da sua respectiva unidade da federação. A contribuição das grandes e complexas aglomerações urbanas à mobilidade laboral é relevante e fundamental à compreensão desse tipo de mobilidade e das redes. Isso é justificado pelo fato de as aglomerações urbanas favorecerem uma possível ascensão social, profissional e diversidade de serviços, com maior presença de universidades.

A descrição desses fluxos mostra que, muitas vezes, os fluxos de mobilidade não correspondem à força de atração das áreas mais próximas; no entanto, há uma proeminência dos fluxos de curta distância, principalmente entre São Paulo e Rio de Janeiro. Com a formação dos laços entre os lugares através dos movimentos recíprocos, e sua posterior permanência, são formadas as diversas redes de mobilidade, cuja distância possui papel fundamental na sua construção e manutenção. ${ }^{4}$

4 Por fugir ao escopo do artigo, migração e mobilidade de retorno e movimento pendular não são analisados aqui. Os autores, porém, compreendem que tais fenômenos são também fundamentais para compreensão da dinâmica da distribuição da população no território e da mobilidade laboral. 


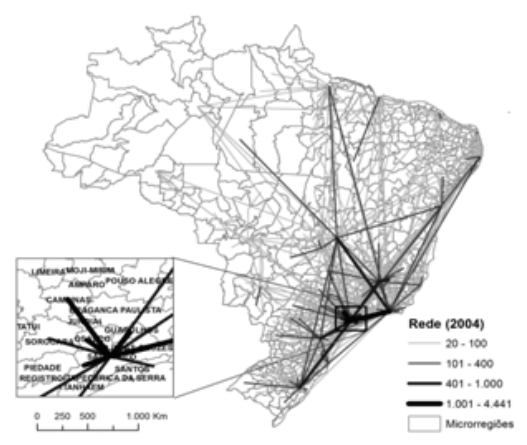

figura 1a

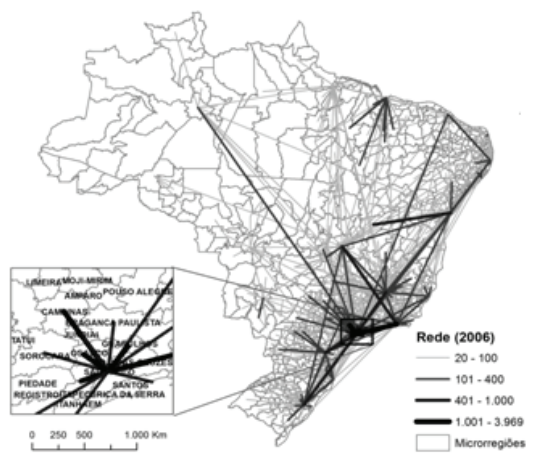

figura 1c

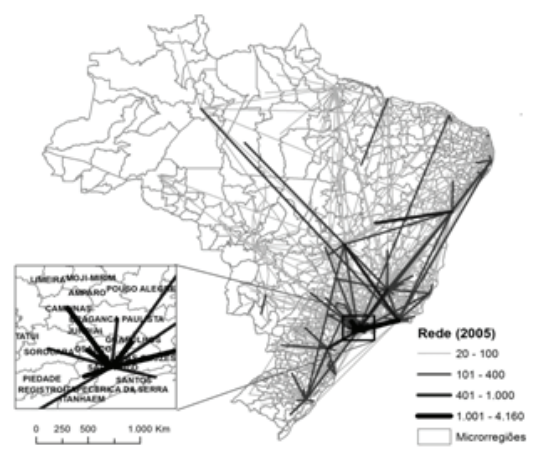

figura $1 \mathrm{~b}$

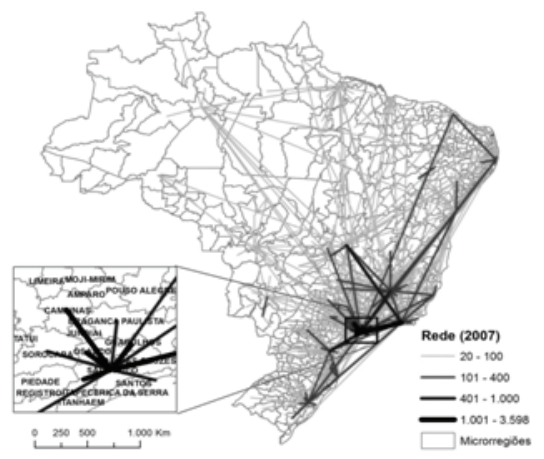

figura 1d

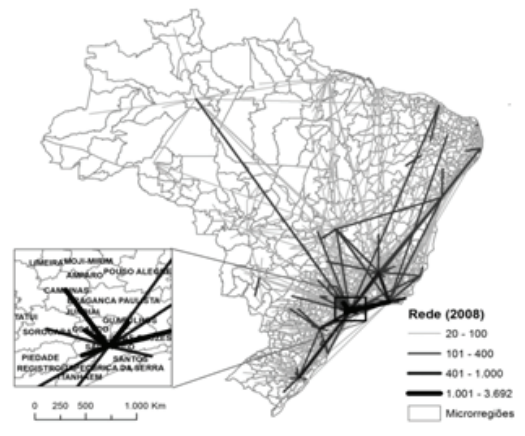

figura 1e

Figura 1: Fluxos de trabalhadores 2004 a 2008.

Fonte: Elaboração dos autores a partir da Rais-Migra. 


\subsection{Análise econométrica}

A análise dos resultados das regressões inicialmente é feita considerando todos os movimentos dos trabalhadores como se a mobilidade de trabalhadores entre as microrregiões fosse um único fenômeno (primeira coluna da Tabela 1). Tendo em vista a análise descritiva da variável dependente em estudo, presente no Quadro 1, o modelo representativo para esse estudo foi o binomial negativo inflado de zeros. Cabe ressaltar, ainda, que foi realizado o teste de Vuong, confirmando o modelo inflado de zeros como de melhor ajuste. $\mathrm{O}$ modelo inflado de zeros possui ainda menores valores para os critérios de informação Akaike (AIC) e Bayesiano (BIC). Sendo assim, a análise será realizada a partir desse modelo.

A variável eficácia migratória, que capta aspectos de rede de mobilidade laboral, apresentou coeficiente positivo e significativo a $1 \%$, indicando preferência por destinos em que há histórico de atração relativa destino/origem. Ao se aumentar o índice de eficácia migratória em uma unidade, o número esperado de trabalhadores que realizariam a mobilidade laboral aumentaria por um fator de 1,07 (esse valor corresponde a $\exp (0,0696))$, mantendo todas as demais variáveis do modelo constantes. Assim, como a migração dá origem a uma rede de relação interpessoal, a integração territorial prévia, caracterizada por uma rede de migrantes, dá origem a posterior fluxo de pessoas, uma vez que facilitam a circulação de informações, diminuindo, por sua vez, o risco e a incerteza nas decisões futuras de mobilidade (Braga e Fazito, 2010; Cunha et al., 2013).

Custos de migração laboral são menores quando há estoque de migrantes já estabelecidos, e a migração tende a seguir canais geográficos anteriores, sendo, por sua vez, implícita a ideia de que movimentos prévios são importantes na escolha por um determinado destino (Carrigton et al., 1996). Como esperado, e em consonância com a literatura, a distância possui relação inversa à mobilidade (Levy e Wadycki, 1974; Andrienko e Guriev, 2004; Pekkala, 2003; Faggian e Royuela, 2010; Biagi et al., 2011; Aldashev e Dietz, 2012; Sahota, 1968; Golgher et al., 2005; Sabbadini e Azzoni, 2006; Sachsida et al., 2010). Um acréscimo de uma unidade de distância, mantendo constantes as outras variáveis no modelo, reduz a taxa de mobilidade de trabalhadores em magnitude de 0,99. 
O PIB per capita apresentou relação negativa com a mobilidade, indicando que regiões com maior produto em relação à origem são preteridas como destino dos trabalhadores, o que representa um resultado oposto ao verificado na literatura. Desse modo, trabalhadores estariam procurando oportunidades em regiões menos ricas. Uma hipótese explicativa para esse resultado é a existência de mobilidade de retorno, que foge, porém, ao escopo desse trabalho.

A variável proporção de trabalhadores com ensino superior apresentou relação positiva com a entrada de trabalhadores. Conforme Moretti (2011), maior estoque de habilidades podem tornar um determinado destino atraente em virtude da possibilidade de interagir e tirar proveito de transbordamentos de conhecimento, aumentando o nível de capital humano dos migrantes. No caso desse artigo, como os fluxos podem estar associados a um perfil de baixa escolaridade, o argumento acima se reforça. ${ }^{5}$

Alta taxa de homicídio no destino em relação à origem expulsa trabalhadores, como esperado, uma vez que a expectativa de vida é reduzida, representando assim uma amenidade negativa. Da mesma forma, a variável veículos/habitantes, proxy para emissão de CO2 e congestionamento, apresentou relação negativa com a entrada de trabalhadores. Sugerindo que trabalhadores preferem destinos nos quais tanto a poluição quanto o congestionamento sejam menores. Este resultado é consistente com custo de vida mais elevado no destino e reforça outros resultados similares obtidos para o Brasil, como em Justo e Silveira Neto (2006), Sabbadini e Azzoni (2006) e Mata et al. (2007).

\footnotetext{
Vale lembrar também que as motivações individuais para mobilidade laboral podem ser diferentes segundo o nível de escolaridade (Grubel e Scott, 1976; Faggian e MCCann, 2009). $\mathrm{O}$ efeito da distância na mobilidade de trabalhadores pode ser distinto para trabalhadores com ou sem ensino superior. Ambos podem ser objeto de pesquisa futura. Nesse trabalho, como forma de verificar robustez dos resultados, foram estimados modelos sem a variável de ensino superior. Os resultados são muito similares.
} 
Tabela 1: Determinantes da mobilidade de trabalhadores no Brasil. Período: 2004 a 2008.

\begin{tabular}{|c|c|c|c|}
\hline Variável dependente: Mij & Todos os Fluxos & $\begin{array}{l}\text { Curta Distância } \\
\text { até } 150 \mathrm{~km}\end{array}$ & $\begin{array}{l}\text { Longa Distância } \\
\text { acima de } 150 \mathrm{~km}\end{array}$ \\
\hline \multirow{2}{*}{ IEMij } & $0,0696^{* \star *}$ & 0,0950 & $0,0549^{* * *}$ \\
\hline & $(0,0139)$ & $(0,0788)$ & $(0,0135)$ \\
\hline \multirow{2}{*}{ Distância } & $-0,0003^{* * *}$ & $-0,0186^{\star * *}$ & $-0,0002^{* * *}$ \\
\hline & $(0,0000)$ & $(0,0006)$ & $(0,0000)$ \\
\hline \multirow{2}{*}{ Contiguidade } & $0,9946^{\star * *}$ & $-0,4628^{\star \star \star}$ & $1,1837^{\star * *}$ \\
\hline & $(0,0145)$ & $(0,0788)$ & $(0,0171)$ \\
\hline \multirow{2}{*}{ Admissões Líquidas } & 0,0000 & $-0,0001$ & 0,0000 \\
\hline & $(0,0000)$ & $(0,0001)$ & $(0,0000)$ \\
\hline \multirow{2}{*}{ Densidade } & 0,0000 & $0,0488^{* * *}$ & 0,0000 \\
\hline & $(0,0000)$ & $(0,0031)$ & $(0,0000)$ \\
\hline \multirow{2}{*}{ Grau de industrialização } & 0,0001 & $-0,0032^{*}$ & 0,0001 \\
\hline & $(0,0003)$ & $(0,0018)$ & $(0,0003)$ \\
\hline \multirow{2}{*}{ PIB per capita } & $-0,0328^{\star \star \star}$ & $-0,1902^{\star \star \star}$ & $-0,0361^{\star \star \star}$ \\
\hline & $(0,0046)$ & $(0,0247)$ & $(0,0045)$ \\
\hline \multirow{2}{*}{ Ensino Superior } & $0,0001^{* * *}$ & $0,0002^{* \star *}$ & $0,0001^{* \star *}$ \\
\hline & $(0,0000)$ & $(0,0000)$ & $(0,0000)$ \\
\hline \multirow{2}{*}{ Taxa de homicídio } & $-0,0183^{\star \star \star}$ & $-0,0699^{\star \star \star}$ & $-0,0132^{* * *}$ \\
\hline & $(0,0018)$ & $(0,0085)$ & $(0,0018)$ \\
\hline \multirow{2}{*}{ Veículos/hab } & $-0,0001^{\star \star *}$ & $-0,0003^{\star \star \star}$ & $-0,0001^{\star *}$ \\
\hline & $(0,0000)$ & $(0,0001)$ & $(0,0000)$ \\
\hline \multirow{2}{*}{ Dummy de ano 2004} & $0,0537^{\star \star \star}$ & 0,0494 & $0,0462^{\star \star \star}$ \\
\hline & $(0,0157)$ & $(0,0549)$ & $(0,0161)$ \\
\hline \multirow{2}{*}{ Dummy de ano 2005} & $0,0491^{\star * *}$ & 0,0107 & $0,0443^{\star \star *}$ \\
\hline & $(0,0157)$ & $(0,0549)$ & $(0,0161)$ \\
\hline \multirow{2}{*}{ Dummy de ano 2006} & $0,0536^{\star \star *}$ & $-0,0744$ & $0,0645^{\star \star \star}$ \\
\hline & $(0,0157)$ & $(0,0548)$ & $(0,0160)$ \\
\hline \multirow{2}{*}{ Dummy de ano 2007} & 0,0061 & $-0,0689$ & 0,0101 \\
\hline & $(0,0157)$ & $(0,0547)$ & $(0,160)$ \\
\hline Dummy de ano 2008 & Omitida & Omitida & Omitida \\
\hline \multirow[t]{2}{*}{ Constante } & $1,8727^{\star \star *}$ & $5,0479^{\star * *}$ & $1,7295^{\star * *}$ \\
\hline & $(0,0137)$ & $(0,0869)$ & $(0,0139)$ \\
\hline Observações & 1554030 & 10970 & 1543060 \\
\hline AIC & 374647,7 & 39267,65 & 331422,7 \\
\hline $\mathrm{BIC}$ & 374868,3 & 39399,1 & 331643,2 \\
\hline Alpha $(\alpha)$ & 1,5101 & 1,5908 & 1,4195 \\
\hline Teste de Vuong & $365,44^{\star \star *}$ & $160,17^{\text {** }}$ & $348,61^{* \star *}$ \\
\hline
\end{tabular}

Nota: Desvio padrão entre parênteses; ${ }^{* * *}$ significante a $1 \%,{ }^{* *}$ significante a $5 \%,{ }^{*}$ significante a $10 \%$.

Fonte: Elaboração própria com base em dados extraídos da Rais-Migra (MTE), CAGED/MTE, DENATRAM, IPEADATA e Google Maps.

Como esperado, e anteriormente mencionado na descrição dos dados, microrregiões contíguas tendem a apresentar maiores fluxos de trabalhadores, resultado semelhante ao verificado para os fluxos migratórios entre mesorregiões, presente no estudo de Golgher et al. (2005). O número esperado de migrantes entre microrregiões 
contíguas no modelo para todos os fluxos é $2,7(\exp (0,9946))$, ou seja, o número esperado de migrantes entre microrregiões contíguas é 2,7 maior do que o verificado para microrregiões não contíguas, mantendo-se fixas as demais variáveis do modelo. Por outro lado, o coeficiente da variável admissões líquidas, que capta a dimensão do mercado de trabalho em determinada microrregião, o da densidade, e o coeficiente da variável grau de industrialização não foram significativos no modelo em que todos os fluxos são considerados.

Os resultados das regressões para os fluxos de curta distância ${ }^{6}$ são apresentados na segunda coluna da Tabela 1. A partir do teste de Vuong, foi confirmado o modelo inflado de zeros como de melhor ajuste. $\mathrm{O}$ modelo inflado de zeros possui ainda menores valores para os critérios de informação Akaike (AIC) e Bayesiano (BIC).

Ao se considerar apenas o fluxo de curta distância, verifica-se histórico de atratividade relativa do destino em relação à origem deixa de ter relevância para a decisão do trabalhador. Este resultado é coerente com o fato de que movimentos à curta distância possuem menor risco e incerteza inerentes, prescindindo, em alguns casos, da rede prévia de migrantes, uma vez que esses destinos mais próximos podem oferecer uma maior possibilidade de retorno em caso de insucesso da primeira mobilidade.

Diferente da regressão geral, a variável densidade populacional, é positivamente relacionada à entrada de trabalhadores, sugerindo maiores oportunidades em regiões densamente povoadas (Sahota, 1968; Levy e Wadycki, 1974; Golgher et al., 2005; Sachsida et al., 2010; Aldashev e Dietz, 2012). Em contrapartida, quanto maiores forem as variáveis PIB per capita, taxa de homicídio, veículos/habitantes no destino frente à origem, menor a entrada de trabalhadores.

A variável grau de industrialização, proxy para desenvolvimento industrial, apresentou relação negativa com a mobilidade de trabalhadores, indicando que ambientes com forte peso industrial podem não mais atrair tantos trabalhadores. É importante notar que esse

${ }^{6}$ A dificuldade de acesso a partir de vias de transporte rodoviário no País pode tornar uma distância física pequena em uma distância efetiva grande. Ou seja, o que seria uma migração de curta distância revela-se efetivamente longa distância. Idealmente, os custos de deslocamento deveriam ser utilizados. Dessa maneira, as estimativas para pequenas distâncias ficam mais frágeis do que as de longas distâncias, uma vez que, para grandes distâncias, estas diferenças de captura de dificuldades de acesso tendem a ser menores. Agradecemos esse ponto ao parecerista anônimo. 
resultado é consistente com o processo de desconcentração industrial pelo qual passa o País, com novas oportunidades de ocupações em localidades pouco industrializadas, e coerente com a provável migração de retorno. Conforme observado por Rigotti (2006), o retorno daqueles menos qualificados de áreas metropolitanas ou de antigas fronteiras para as áreas de origem no interior do Brasil possui papel expressivo no processo migratório mais atual.

Os resultados são um pouco diferentes para o modelo de longa distância (terceira coluna da Tabela 1). A variável densidade populacional, cujo coeficiente foi positivo e significativo a $1 \%$ para curta distância, não apresentou relação com entrada de trabalhadores. A proxy para dinamismo no mercado de trabalho, admissões líquidas, não apresentou coeficiente significativo nos deslocamentos a longas distâncias. O grau de industrialização, relevante para os movimentos de curta distância, não apresentou importância nos deslocamentos a longa distância. Por outro lado, o coeficiente da variável veículos/ habitante, proxy para congestionamento, na mobilidade de longa distância foi negativo e significativo, resultado semelhante ao verificado para curtas distâncias.

Custos associados a movimentos longos tendem a ser maiores se comparados aos de curta distância, envolvendo maior grau de incerteza, ainda que essa seja abrandada pela existência de rede migratória anterior ao movimento. Na mobilidade de curta distância, existe ainda a possibilidade de se conhecer ou verificar as condições laborais e de vida no destino antes da etapa migratória. Isso pode explicar ainda a diferença na magnitude dos fluxos de curta e longa distâncias, bem como a não significância do coeficiente da variável IEMij em fluxos a curtas distâncias.

Em resumo, as outras variáveis apresentaram resultados similares aos das regressões geral e de curta distância. Vale lembrar que, para todas as regressões, o modelo binomial negativo inflado de zeros apresentou melhor ajuste, permitindo confirmar, sobretudo, a importância das conexões prévias, além de algumas outras variáveis econômicas e de amenidades, na explicação dos fluxos de mobilidade de trabalhadores no período. 


\section{Conclusões}

Este artigo teve como principal objetivo a identificação dos determinantes econômicos e sociais da mobilidade laboral, com ênfase no papel da rede de migrantes, entendida como o histórico de atratividade ou conexão. Esse objetivo foi analisado em função de diferentes cortes de distância, a fim de detectar possíveis diferenças nos padrões de mobilidade entre curta e longa distância.

Foram apresentadas evidências de que redes ou conexões facilitam a mobilidade laboral, uma vez que diminuem o risco de mobilidade mal sucedida ao diminuírem o grau de incerteza associado ao movimento. Ao avaliar a mobilidade de curta e longa distância, nota-se que o trabalhador se desloca para destinos com maiores densidade populacional, proporção de graduados e atração relativa, além de menores criminalidade e veículos por habitante.

No caso específico dos fluxos de curta distância, o trabalhador se desloca para destinos com maior densidade populacional e entrada de trabalhadores, sugerindo maiores oportunidades em regiões densamente povoadas, com maiores oportunidades de emprego, embora o nível de riqueza, medido pelo PIB per capita, não tenha se mostrado como fator atrator, mas sim repulsor, assim como o grau de industrialização. Além disso, a taxa de homicídio e a razão veículos por habitante no destino em relação à origem são negativamente associadas à mobilidade. Ressalta-se a evidência de existir maior intensidade dos fluxos a menores distâncias.

Os resultados são um pouco diferentes para o modelo de longa distância. A variável densidade populacional não apresentou relação com entrada de trabalhadores. De maneira semelhante, o grau de industrialização não apresentou coeficiente estatisticamente significativo. Cabe destacar que a distância figura como fator inibidor para a mobilidade, fato que independe da extensão espacial dos movimentos dos trabalhadores.

A partir das evidências do presente estudo, o papel das redes de mobilidade prévias e a distância, considerando-se diferentes critérios de extensão territorial, constituem importantes fatores determinantes da mobilidade laboral no Brasil. 


\section{Referências}

ADAMS, J.; FAUST, K.; LOVASI, G. S. Capturing context: integrating spatial and social network analyses, Editorial in Social Networks, v. 34 p. 1-5 January. 2012.

ALDASHEV, A.; DIETZ, B. Economic and Spatial Determinants of Interregional Migration in Kazakhstan. Bonn: The Institute for the Study of Labor (IZA), 2012. (Working paper, 6269).

ANDRIENKO, Y.; GURIEV, S. Determinants of Interregional Mobility in Russia: Evidence from Panel Data. Economic of Transition, v. 12, p. 1-27. 2004.

BAENINGER, R. Novos Espaços da Migração no Brasil: Anos 80 e 90. In: ENCONTRO TRANSDISCIPLINAR SOBRE ESPAÇO E POPULAÇÃO \& ENCONTRO NACIONAL SOBRE MIGRAÇÕES. 3, 2003, Campinas. Anais. Campinas: NEPO/ABEP, 2003.

BAENINGER, R. Rotatividade Migratória: um novo olhar para as migrações no século XXI. In: XVI Encontro Nacional de Estudos Populacionais, 2008, Caxambu, MG. Anais. São Paulo: ABEP, 2008.

BEALS, R., LEVY, M., MOSES, L. Rationality and Migration in Ghana. The Review of Economics and Statistics, v. 49, n. 4, p. 480-486, 1967.

BIAGI, B.; FAGGIAN, A.; McCANN, P. Long and short distance migration in Italy: the role of economic, social and environmental characteristics. Spatial Economic Analysis, v. 6, n. 1, p. 111-131, 2011.

BRAGA, F. G.; FAZITO, D. Análise de redes sociais e as conexões territoriais da migração no Brasil: padrões estruturais da migração interna entre 1980 e 2000. In: XVII Encontro Nacional de Estudos Populacionais, 2010, Caxambu. Anais. São Paulo: ABEP, 2010.

CAMERON, A. C. e TRIVEDI, P. K. Microeconometrics: methods and applications. Cambridge University press, 2005.

CAMERON, A. C. e TRIVEDI, P. K. Regression analysis of count data. Cambridge; New York: Cambridge University Press; 1998.

CARRINGTON, W. J.; DETRAGIACHE, E.; VISHWANATH, T. Migration with Endogenous Moving Costs. American Economic Review, v. 86, n. 4, p. 909-930, 1996.

CENSO DEMOGRÁFICO 2010. Trabalho e rendimento: resultados da amostra. Rio de Janeiro: IBGE, 2012. Disponível em: http://www.ibge.gov.br/home/estatistica/populacao/censo2010/ trabalho_e_rendimento/default.shtm>. Acesso em: dez.2013.

CUNHA, T. A.; CUNHA, J. M. P.; JAKOB, A. A. E. Dinâmica intraurbana e redes sociais na Baixada Santista. Revista Brasileira de Estudos de População, Rio de Janeiro, v. 30, n. 1, p. 7-33, jan./ jun. 2013.

ERVATTI, L. R.; OLIVEIRA, A. T. R. Perspectivas para a mensuração do fenômeno migratório no Brasil. In: Reflexões Sobre os Deslocamentos Populacionais no Brasil. Rio de Janeiro: Instituto Brasileiro de Geografia e Estatística - IBGE, Estudos e Análises Informação Demográfica e Socioeconômica v. 1, p. 84-100. 2011.

FAGGIAN, A., MCCANN, P. Human capital and regional development. In, Capello, Roberta and Nijkamp, Peter (eds.) Handbook of Regional Growth and Development Theories. Cheltenham, UK, Edward Elgar, p. 131-151. 2009.

FAGGIAN, A.; ROYUELA, V. Migration flows and quality of life in a metropolitan area: the case of Barcelona - Spain. Applied Research in Quality of Life, v. 5, n. 3, p. 241-259. 2010.

FAZITO, D. Redes Sociais e Migração: mito e realidade. In: ENCONTRO DAASSOCIAÇÃO BRASILEIRA DE ESTUDOS POPULACIONAIS, 13, 2002, Ouro Preto. Anais. Ouro Preto: ABEP, 2002.

FERREIRA, R. N.; MATOS, R. Migração de trabalhadores no mercado formal brasileiro entre 1995 e 2003 e as tendências da reestruturação territorial. In: ENCONTRO NACIONAL DE ESTUDOS POPULACIONAIS, 14, 2004, Caxambu. Anais. Belo Horizonte: ABEP, 2006. 
FLORIDA, R. The Economic Geography of Talent. In: ANNALS OF THE ASSOCIATION OF AMERICAN GEOGRAPHERS, v. 92, n. 4, p. 743-755. 2002.

GLAESER, E. L. Learning in cities. Journal of Urban Economics, v. 46, n. 2, p. 254-277, 1999.

GOLGHER, A. Fundamentos da migração. Belo Horizonte: UFMG/CEDEPLAR, 2004. (Texto para discussão, 231).

GOLGHER, A. B.; ROSA, C. H.; ARAÚJO JÚNIOR, A. F. The determinants of migration in Brazil. Belo Horizonte: UFMG/CEDEPLAR, 2005. (Texto para discussão, 268).

GRAVES, P. A reexamination of migration, economic opportunity, and the quality of life, Journal of Regional Science, v. 12, p. 107-112. 1976.

GRAVES, P. Migration and climate, Journal of Regional Science, v. 20, p. 227-237. 1980.

GRAVES, P. Migration with a composite amenity: the role of rents. Journal of Regional Science, v. 23, p. 541-546. 1983.

GREENWOOD, M. J. Research on Internal Migration in the United States: a survey, Journal of Economic Literature, v. 13, p. 397-433. 1975.

GREENWOOD, M. J.; HUNT, G. Migration and interregional employment redistribution in the United States, American Economic Review, v. 74, p. 957-969. 1984.

GRUBEL, H.G. e SCOTT, A. The brain drain: determinants, measurement and welfare effects. Canadá: Waterloo, 1.ed. 1976.

GUILMOTO, C.Z:; SANDRON, F. The internal dynamics of migration networks in developing countries. In Population: an English Selection, v. 13, n. 2, p. 135-164. 2001.

HAZANS, M. Determinants of inter-regional migration in the Baltic countries. Bonn: The Institute for the Study of Labor (IZA), 2003. (Working paper B17).

INSTITUTO BRASILEIRO DE GEOGRAFIA E ESTATÍSTICA -IBGE. Divisão do Brasil em mesorregiões e microrregiões geográficas. Rio de Janeiro: IBGE, 1990. 20p. (Relatório Técnico)

JACKMAN, R.; SAVOURI, S. Migration in Britain: An Analysis of Gross Flows Using NHS Central Register Data. The Economics Journal, v. 102, n. 415, pp. 1433-1450. 1992.

JARDIM, A. P. A investigação das migrações internas, a partir dos censos demográficos brasileiros de 1970 a 2010. In: Reflexões Sobre os Deslocamentos Populacionais no Brasil. Rio de Janeiro: Instituto Brasileiro de Geografia e Estatística - IBGE, Estudos e Análises Informação Demográfica e Socioeconômica v. 1, p. 11-27. 2011.

JUSTO, W. R.; SILVEIRA NETO, R. M. Migração inter-regional no Brasil: Evidências a partir de um modelo espacial. Revista Economia, v.7, n. 1, p.163-187, Jan/Jul. 2006.

LEVY, M. B.; WADYCKI, W. J. What is the Opportunity Cost of Moving? Reconsideration of the Effects of Distance on Migration. Economy, Development and Cultural Change, v. 22, p. 198-214. 1974.

LIMA, E. E. C.; BRAGA, F. Da rotatividade migratória a baixa migração: uma análise dos novos padrões da mobilidade populacional no Brasil. In: ENCONTRO NACIONAL DE ESTUDOS POPULACIONAIS, 17, 2010, Caxambu. Anais. Caxambu: ABEP, 2010.

LUCAS, R. E. B. The effects of proximity on developing country population migrations. Journal of Economy Geography, Boston, v. 1, n. 3, p. 323-339, 2001.

MATA, D. da; OLIVEIRA, C.; PIN, C.; RESENDE, G. Quais Características das Cidades Determinam a Atração de Migrantes Qualificados? Revista Econômica do Nordeste, Fortaleza, v. 38, n. 3, jul-set, 2007.

MATOS, R.; F. BRAGA. Redes Sociais, Redes Territoriais e Migrações. In: XIV ENCONTRO NACIONAL DE ESTUDOS POPULACIONAIS, 14, 2004, Caxambu. Anais. Belo Horizonte: ABEP, 2004.

MORETTI, E. Local labor markets. In: CARD, D., ASHENFELTER, O. (Eds.), Handbook of Labor Economics, V. 4, Part B, Chapter 14, p. 1237-1313, 2011. 
NETTO JR, J. L. S.; MOREIRA, I. T. Migrações e diferenciais de renda estaduais: uma análise por dados em painel no período de 1950-2000. In: ENCONTRO TRANSDISCIPLINAR SOBRE ESPAÇO E POPULAÇÃO \& ENCONTRO NACIONAL SOBRE MIGRAÇÕES. 3, 2003, Campinas. Anais. Campinas: NEPO/ABEP, 2003.

OLIVEIRA, A. T. R. De. Algumas abordagens teóricas a respeito do fenômeno migratório. In: Reflexões Sobre os Deslocamentos Populacionais no Brasil. Rio de Janeiro: Instituto Brasileiro de Geografia e Estatística - IBGE, Estudos e Análises Informação Demográfica e Socioeconômica v. 1, p. 11-27. 2011.

OLIVEIRA, A. T. R.; ERVATTI, L. R.; O’NEILL, M. M. V. C. O panorama dos deslocamentos populacionais no Brasil: PNADs e Censos Demográficos. In: Reflexões Sobre os Deslocamentos Populacionais no Brasil. Rio de Janeiro: Instituto Brasileiro de Geografia e Estatística - IBGE, Estudos e Análises Informação Demográfica e Socioeconômica v. 1, p. 29-49. 2011

PATARRA, N. L. Movimentos migratórios no Brasil: tempos e espaços. Rio de Janeiro: IBGE, 2003. 45p. (Texto para discussão, 7).

PEKKALA, S. Migration Flows in Finland: Regional Differences in Migration Determinants and Migrant Types. International Regional Science Review, v. 26, n. 4, p. 466-482.

RAMOS, C. A.; ARAÚJO, H. Fluxos migratórios, desemprego e diferenciais de renda. Rio de Janeiro: Ipea, 1999. (Texto para discussão, 657).

RIGOTTI, J. I. R. Geografia dos fluxos populacionais segundo níveis de escolaridade dos migrantes. Estudos Avançados (USP. Impresso), v. 20, p. 237-254, 2006.

SABBADINI, R.; AZZONI, C. R. Migração interestadual de pessoal altamente educado. Evidências sobre a fuga de cérebros. ENCONTRO NACIONAL DE ECONOMIA, 34, 2006, Salvador. Anais. Salvador: ANPEC, 2006.

SACHSIDA, A.; CAETANO, M. A.; ALBUQUERQUE, P. Distribuição de Renda, Transferências Federais e Imigração: Um estudo de dados em painel para as unidades de federação do Brasil. Brasília: IPEA, 2010. (Texto para discussão, 1471).

SAHOTA, G. S. An Economic analysis of Internal Migration in Brazil. Journal of Political Economy, v.76, n.2, p.218-245, 1968.

SCHWARTZ, A. Interpreting the Effect of Distance on Migration. Journal of Political Economy, v. 81, p. 1153-1169. 1973.

SOARES, W. Da metáfora a substância: Redes Sociais, Redes Migratórias e Migração nacional e internacional em Valadares e Ipatinga. 2002. Tese (Doutorado em Demografia) - Centro de Desenvolvimento e Planejamento Regional, Universidade Federal de Minas Gerais, Belo Horizonte, 2002.

STAMBOL, L. Regional labor market mobility by education and income. Economic Survey. 2/2003, Statistics Norway.

STARK, O.; JAKUBEK, M. Migration networks as a response to financial constraints: onset and endogenous dynamics, Journal of Development Economics, v. 101, p. 1-7. 2013.

STOUFFER, S. A. "Intervening Opportunities: A Theory Relating Mobility and Distance." American Sociological Review, v. 5, n. 6, p. 845-867. 1940.

TRUZZI, O. M. S. Redes em processos migratórios. Tempo Social. São Paulo, v. 20, p. 199-218, 2008.

WALL, H. J. Voting with your feet in the United Kingdom: Using cross-migration rates to estimate relative living standards. Papers in Regional Science, v. 80, p.1-23. 2001.

WOOLDRIDGE, J. M. Econometric analysis of cross section and panel data. MIT Press: London, 2002.

ZIMMERMANN, K.F. European labour mobility: challenges and potentials. Berlin: University of Bonn and DIW, 2004. 


\section{Apêndice:}

Tabela Al: Matriz de correlação entre as variáveis explicativas.

\begin{tabular}{|c|c|c|c|c|c|c|c|c|c|}
\hline & Distância & Adliq & Dens & Ind & PIBpc & Sup & Txhom & $\mathrm{Vh}$ & IEMij \\
\hline Distancia & 1,000 & & & & & & & & \\
\hline $\begin{array}{l}\text { Admissões } \\
\text { Líquidas }\end{array}$ & 0,001 & 1,000 & & & & & & & \\
\hline Densidade & 0,076 & 0,102 & 1,000 & & & & & & \\
\hline $\begin{array}{l}\text { Grau de } \\
\text { industrialização }\end{array}$ & 0,025 & 0,024 & 0,008 & 1,000 & & & & & \\
\hline PIB per capita & 0,112 & 0,081 & 0,054 & 0,189 & 1,000 & & & & \\
\hline Ensino Superior & $-0,007$ & 0,116 & 0,031 & 0,006 & 0,037 & 1,000 & & & \\
\hline $\begin{array}{l}\text { Taxa de } \\
\text { Homicídio }\end{array}$ & 0,006 & 0,026 & 0,042 & 0,179 & 0,245 & 0,037 & 1,000 & & \\
\hline Veículos/hab & 0,019 & 0,008 & $-0,001$ & $-0,001$ & 0,079 & 0,007 & $-0,012$ & 1,000 & \\
\hline IEMij & 0,000 & $-0,009$ & $-0,008$ & 0,000 & 0,006 & $-0,000$ & 0,000 & $-0,000$ & 1,000 \\
\hline
\end{tabular}

Fonte: Elaboração própria.

Tabela A2: Teste de Sobredispersão dos dados: Poisson contra Binomial negativo $\left(\mathrm{H}_{0}\right.$ : não há sobredispersão)

\begin{tabular}{ccc}
\hline Amostra Total & Curta distância & Longa distância \\
$160.963,76$ & $48.731,82$ & $57.724,52$ \\
\hline
\end{tabular}

Fonte: Elaboração própria. 